\title{
Nickel Microneedles Fabricated by Sequential Copper and Nickel Electroless Plating and Copper Chemical Wet Etching
}

\author{
Phill Gu Jung , Tae Won Lee ${ }^{1}$, Dong Joon Oh¹, Sung Jin Hwang ${ }^{1}$, \\ Im Deok Jung ${ }^{2}$, Sang Min Lee ${ }^{2}$ and Jong Soo $\mathrm{Ko}^{1,2, *}$ \\ ${ }^{1}$ Graduate School of Mechanical Engineering, Pusan National University, \\ Jangjeon-dong, Geumjeong-gu, Busan 609-735, Korea \\ ${ }^{2}$ Interdisciplinary Program in Microelectromechanical Systems, Pusan National University, \\ Jangjeon-dong, Geumjeong-gu, Busan 609-735, Korea
}

(Received July 30, 2007; accepted October 16, 2007)

Key words: microneedle, electroless plating, chemical etching

Nickel microneedles have been fabricated by a sequential process of electroless copper and nickel plating and copper wet chemical etching. An electroless plating solution was injected using an external syringe pump and made to flow through the inside of a copper base tube. The temperature gradient along the length of the copper base tube brings about different plating thicknesses along its length, resulting in a wide inlet and a sharp end with a microaperture. The diameter of the microaperture could be readily controlled by plating time such that microneedles with various diameters could be easily acquired. To verify their applicability, the fabricated microneedles have been applied to a probe for cell capturing and to a needle for microdispensing.

\section{Introduction}

With the rapid development of the microfluidics-based industry, including the expansion of the use of microdispensers, drug delivery systems (DDSs), and biochips, there has been an increasing demand for microneedles. ${ }^{(1-3)}$ For decades, researchers have sought appropriate materials and fabrication techniques for microneedles. ${ }^{(4-9)}$ To date, glass, silicon, and polymers have provided the primary materials for microneedles. ${ }^{(10-14)}$ While glass and silicon have good surface properties and high mechanical strength, polymers offer good biocompatibility, relatively low production cost, and ease of fabrication. Although these materials have numerous

*Corresponding author: e-mail: mems@pusan.ac.kr 
advantages, each has respective drawbacks as well. Glass and silicon are too brittle and are thus vulnerable to shock and bending. Microneedles made with glass are therefore usually applied to micropipettes. However, in spite of concern for applications for the human body, NanoPass Technologies Ltd. has succefully developed and is now selling hollow microneedles made of silicon for intradermal injections and solid microprojections for consmetic enhancement. ${ }^{(13)}$ Polymers meanwhile lack sufficient strength and as such are easily bent. Microneedles made from polymers have thus been mainly exploited as fluidic interconnects or conduits. Overall, glass and polymer microneedles are not readily applicable to areas requiring good mechanical properties.

In contrast, metals have good mechanical properties such as strength, toughness, and thermal conductivity. Furthermore, they also provide good electrical conductivity. Thus, microneedles made from metals can feasibly be utilized in various applications requiring solid mechanical properties, such as injectors, spotters, and nozzles.

Minute metal tubes have generally been fabricated by conventional processes such as extrusion, drawing, and electrical discharge machining (EDM). ${ }^{(15-19)}$ Using these conventional fabrication processes, however, it is very difficult to fabricate metal microneedles with a fine aperture. Recently, several research groups have developed metal microneedles using micromachining technology that involves photolithography and electroplating. ${ }^{(20,21)}$ In particular, Sumitomo Electric Industries introduced a novel fabrication concept using electroplating for nickel microneedles, which are currently being commercially produced. These nickel microneedles are fabricated by two sequential processes; electroplating on the outer wall of a sacrificial core post and etching of the sacrificial core post. The fabricated microneedles are not only very clean and uniform but also retain good mechanical properties. However, because the inner diameter of these microneedles depends on the outer diameter of the sacrificial core post, it is also difficult to produce microneedles with a very small inner diameter. In this paper, we present a novel nickel microneedle fabrication method involving sequential electroless copper and nickel plating on the inner wall of a sacrificial copper base tube and the etching of an outer copper layer. In addition, the applicability of the fabricated microneedles is verified for a cell capturing probe and a microdispensing needle. Details are reported herein.

\section{Concept}

Figure 1 shows a fabrication concept for a nickel microneedle. Copper electroless plating solution flows through the inside of the copper base tube, resulting in copper deposition onto its inner wall (Fig. 1(a)). The inner diameter of the copper base tube decreases as the copper electroless plating progresses. Subsequently, nickel electroless plating is conducted (Fig. 1(b)). The nickel electroless plating process similarly reduces the inner diameter of the tube (Fig. 1(c)). A sharp nickel microneedle is thereafter exposed by selective copper etching at the end of the tube (Fig. 1(d)). The outer diameter of the nickel microneedle is determined by the thickness of the plated copper. The increase in thickness of the plated copper layer results in a decrease in the outer diameter of the nickel tube, thereby yielding a sharp-ended microneedle. 
(a)

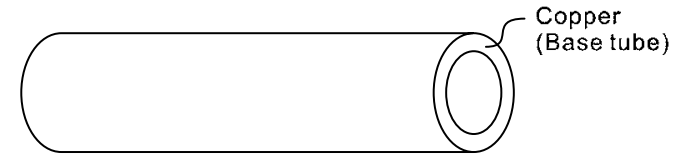

(b)

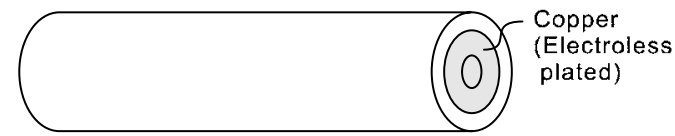

(c)

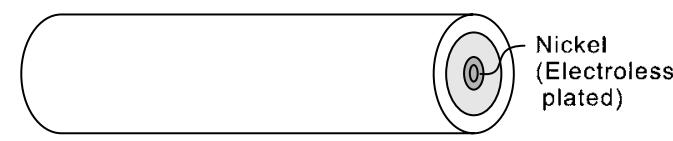

(d)

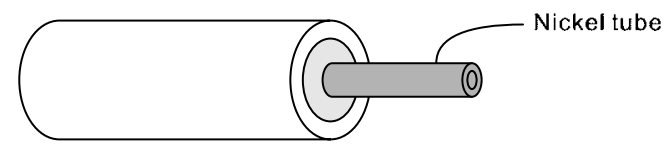

Fig. 1. Fabrication concept for a nickel microneedle: (a) copper base tube; (b) copper electroless plating; (c) nickel electroless plating; (d) copper etching at the tip.

\section{Fabrication}

Figure 2 depicts the experimental setup for electroless plating. The plating and washing solutions are injected using a pump. The outlet part of the copper sacrificial base tube is fixed onto a digital hot plate. Thus, while the inlet part is kept cool, the temperature at the outlet part is almost the same as that of the hot plate, if the plating solution flows very slowly. Because of the temperature gradient along the length of the copper base tube, the thickness of the plated metal also varies. Owing to the relatively low temperature, very little plating occurs at the inlet part of the tube. The experimental setup was arranged so as to produce a nickel microneedle with a sharp end.

Figure 3 illustrates the fabrication process in detail, showing a cross-sectional cut along the longitudinal direction of the tube. The fabrication process starts with the cleaning of the copper base tube, whose inner and outer diameters are 65 and $145 \mu \mathrm{m}$, respectively (Fig. 3(a)). To remove organic materials adhering to the inside of the tube, a degreasing solution mixed with sodium carbonate $\left(\mathrm{Na}_{2} \mathrm{CO}_{3}, 24 \mathrm{~g} / \mathrm{L}\right)$, sodium phosphate $\left(\mathrm{NaPO}_{4}, 24 \mathrm{~g} / \mathrm{L}\right)$, and deionized water was made to flow through the tube. The degreasing process was conducted at a solution temperature of $60^{\circ} \mathrm{C}$ with a flow rate of $10 \mathrm{ml} / \mathrm{h}$ for $3 \mathrm{~min}$. To increase the adhesion between the copper base tube and the plated copper, the inner surface of the copper base tube was etched with 5\% sulfuric acid at $30^{\circ} \mathrm{C}$ for $1 \mathrm{~min}$. As the final process of cleaning, palladium dichloride $\left(\mathrm{PdCl}_{2}\right)$ solution was made to flow through the tube to enhance the surface activity at a solution temperature of $30^{\circ} \mathrm{C}$ for $1 \mathrm{~min}$. 


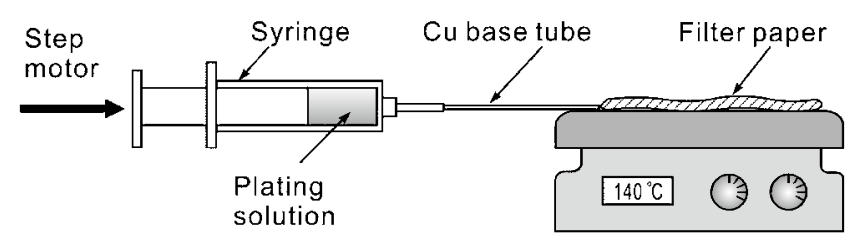

Fig. 2. Experimental setup for electroless plating.

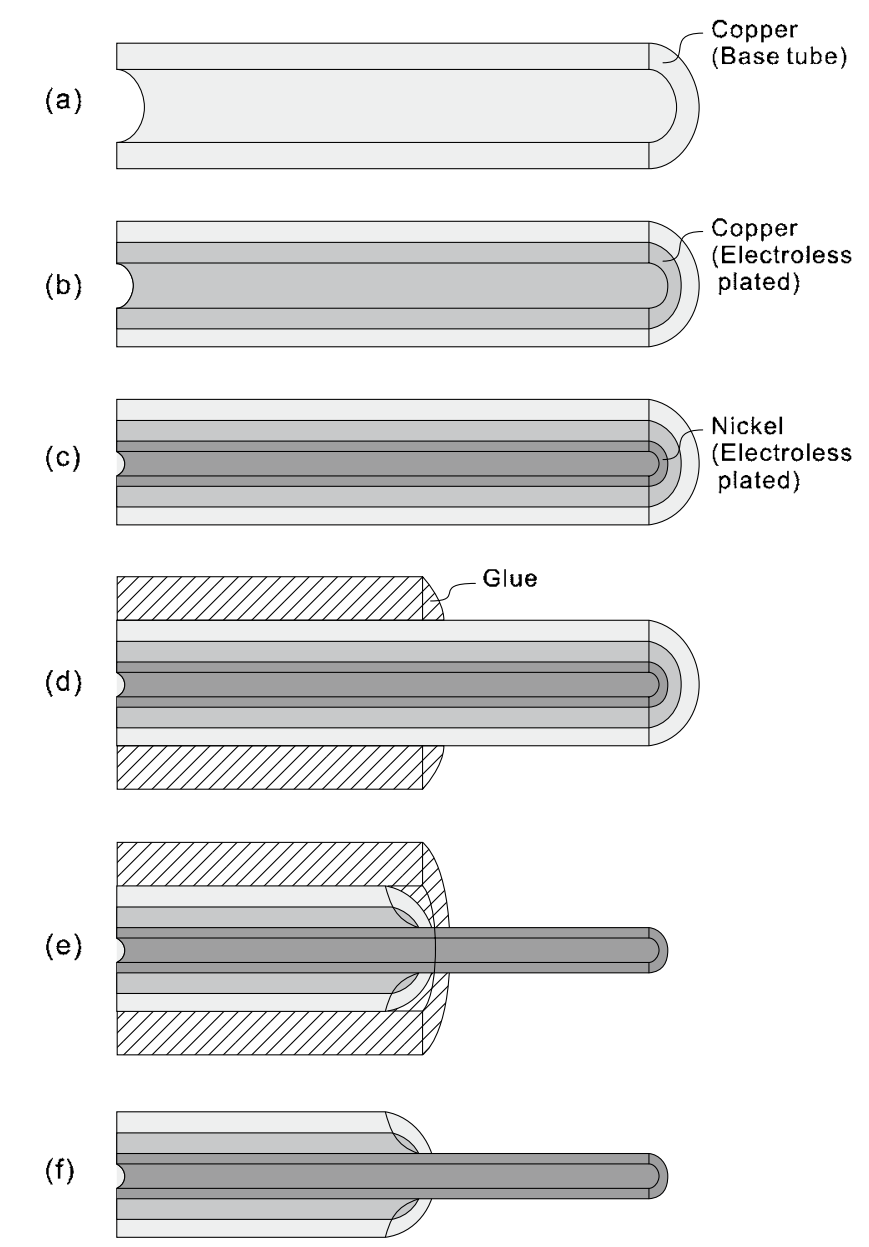

Fig. 3. Fabrication process of microneedle: (a) copper base tube; (b) copper electroless plating; (c) nickel electroless plating; (d) instant glue coating; (e) copper wet etching; (f) removal of instant glue. 
After the cleaning process, copper electroless plating was conducted, followed by nickel electroless plating (Figs. 3(b) and 3(c)). The copper and nickel plating solutions used and their plating conditions are summarized in Table 1. After each plating process, the inside of the tube was immediately and thoroughly rinsed with deionized water. Then, except for the tip region, the outer surface of the tube was coated with cyanoacrylic-based instant glue (Fig. 3(d)). The opened tip part was immersed in a copper etching solution composed of $1 \%$ acetic acid, $1 \%$ hydrogen peroxide, and $5 \%$ deionized water in volume ratio. The copper etch rate in the solution was measured to be $0.5 \mu \mathrm{m} / \mathrm{min}$ at room temperature. The copper base tube and the electroless plated copper were sequentially etched so that a sharp nickel tip was exposed at the end of the copper tube (Fig. 3(e)). The fabrication process was completed with the removal of the instant glue using acetone (Fig. 3(f)).

\section{Fabrication Results and Discussion}

SEM images of a copper base tube and fabricated microneedles are shown in Figs. 4 and 5, respectively. The microneedles shown in Figs. 5(a) and 5(b) were obtained using the plating conditions of process condition numbers 1 and 2, respectively, in Table 1. Except for the plating time, the process conditions are identical. The inner and outer diameters of the microneedle shown in Fig. 5(a), which was plated with a copper plating time of $10 \mathrm{~h}$ and a nickel plating time of $2 \mathrm{~h}$, were measured to be 19 and $30 \mu \mathrm{m}$, respectively. The inner and outer diameters of the microneedle shown

Table 1

Electroless plating solutions and their plating conditions.

\begin{tabular}{|c|c|c|c|c|}
\hline & \multicolumn{2}{|c|}{ Process condition No. 1} & \multicolumn{2}{|c|}{ Process condition No. 2} \\
\hline & $\begin{array}{c}\text { Copper } \\
\text { electroless } \\
\text { plating }\end{array}$ & $\begin{array}{c}\text { Nickel } \\
\text { electroless } \\
\text { plating }\end{array}$ & $\begin{array}{c}\text { Copper } \\
\text { electroless } \\
\text { plating }\end{array}$ & $\begin{array}{c}\text { Nickel } \\
\text { electroless } \\
\text { plating }\end{array}$ \\
\hline Solution & Copper sulfate & $\begin{array}{c}\text { Nickel } \\
\text { phosphorous }\end{array}$ & Copper sulfate & $\begin{array}{c}\text { Nickel } \\
\text { phosphorous }\end{array}$ \\
\hline $\begin{array}{l}\text { Temperature } \\
\text { (hot plate) }\end{array}$ & $100^{\circ} \mathrm{C}$ & $140^{\circ} \mathrm{C}$ & $100^{\circ} \mathrm{C}$ & $140^{\circ} \mathrm{C}$ \\
\hline Plating time & $10 \mathrm{~h}$ & $3 \mathrm{~h}$ & $2 \mathrm{~h}$ & $12 \mathrm{~h}$ \\
\hline Flow rate & $1 \mathrm{ml} / \mathrm{h}$ & $1 \mathrm{ml} / \mathrm{h}$ & $1 \mathrm{ml} / \mathrm{h}$ & $1 \mathrm{ml} / \mathrm{h}$ \\
\hline
\end{tabular}




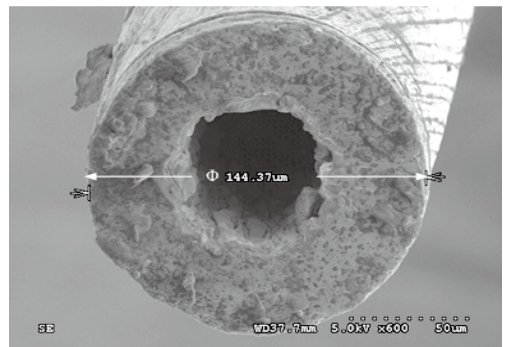

(a)

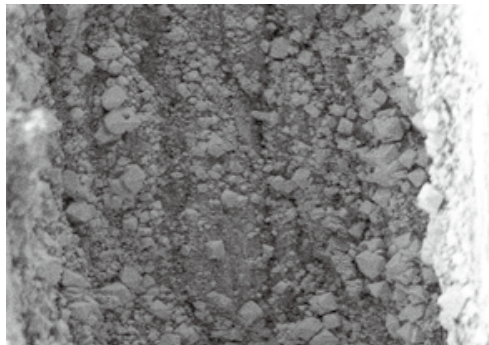

(b)

Fig. 4. SEM images of a copper base tube: (a) inner diameter of $65 \mu \mathrm{m}$ and outer diameter of 145 $\mu \mathrm{m}$; (b) interior surface of the copper base tube.
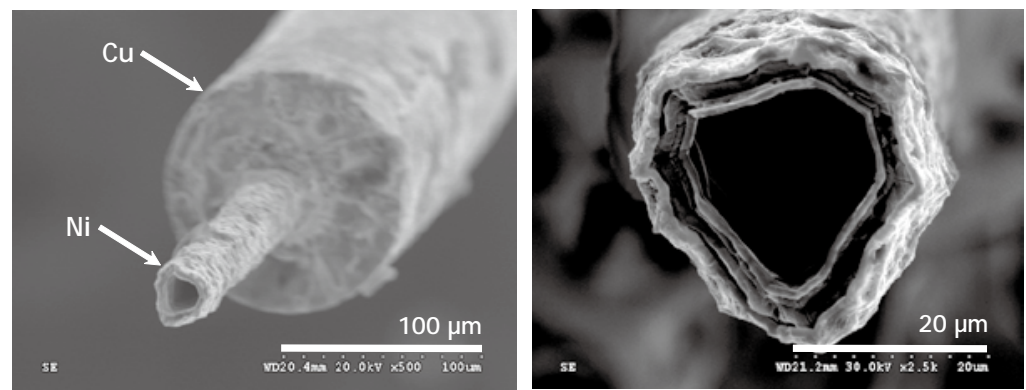

(a)
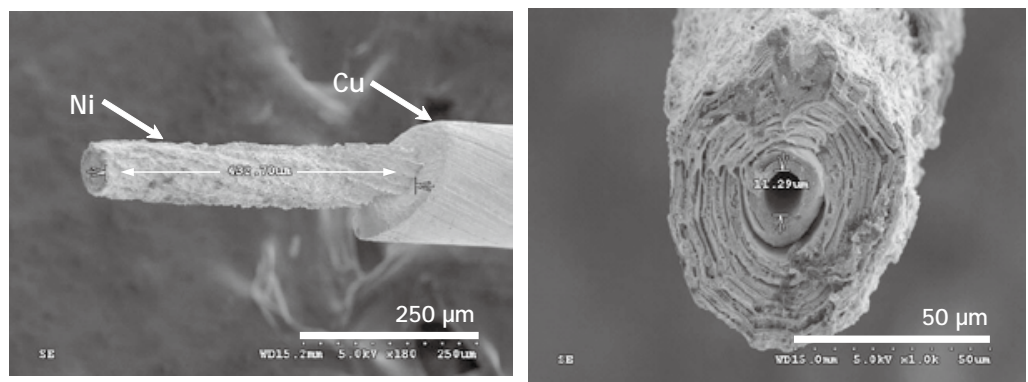

(b)

Fig. 5. SEM images of fabricated microneedles: (a) inner diameter of $19 \mu \mathrm{m}$ and outer diameter of $30 \mu \mathrm{m}$, obtained using process condition No. 1; (b) inner diameter of $11 \mu \mathrm{m}$ and outer diameter of $60 \mu \mathrm{m}$, obtained using process condition No. 2 .

in Fig. 5(b), which was plated with a copper plating time of $2 \mathrm{~h}$ and a nickel plating time of $12 \mathrm{~h}$, were measured to be 11 and $60 \mu \mathrm{m}$, respectively. These fabrication results indicate that the inner and outer diameters of the nickel microneedles can be modified by varying the plating time. A sharp end with a fine aperture can be easily obtained by 
increasing the copper plating time and decreasing the nickel plating time. Microneedles with various diameters can be easily realized through the proposed fabrication method. However, as shown in Fig. 5, the surface of the fabricated nickel microneedle is very rough. The reason is that the original inner surface of the copper base tube is rough, as shown in Fig. 4. If the original inner surface were smooth, a nickel microneedle with a smooth surface could be obtained. As the thickness of the plated metal is increased, the inner diameter of the microneedles becomes smaller, resulting in higher flow resistance. Under the present experiment conditions, owing to the flow resistance, it proved difficult to obtain microneedles with an inner diameter smaller than $10 \mu \mathrm{m}$.

\section{Applications}

\subsection{Microprobe for cell capturing}

The fabricated microneedles have been applied to a microprobe for cell capturing and a micronozzle for microdispensing. The microneedle was connected to a polymer tube that was manipulated using a precision xyz stage. Figure 6 shows microscopic images of the fabricated microneedle capturing an oral epithelial cell. The microneedle was successfully used to deliver and release the oral epithelial cell as well.

\subsection{Micronozzle for microdispensing}

The fabricated microneedle was installed as a dispensing needle in a commercial contact angle meter. Table 2 shows a comparison of the measured contact angles between a $22 \mathrm{G}$ commercial dispensing nozzle with an inner diameter of $483 \mu \mathrm{m}$ and the fabricated micronozzle with an inner diameter of $19 \mu \mathrm{m}$. The micronozzle generated a tiny water drop of $0.7 \mu \mathrm{l}$, as compared with the $11.6 \mu \mathrm{l}$ drop formed by the commercial needle. It is well known that, because of the gravity effect, the volume of the water drop affects the contact angle. The measured contact angles for the micronozzle were $6^{\circ}$ higher than those for the commercial needle. These test results indicate that the fabricated microneedles are readily applicable to microsystems including microprobes, microdispensers, and microinjectors.

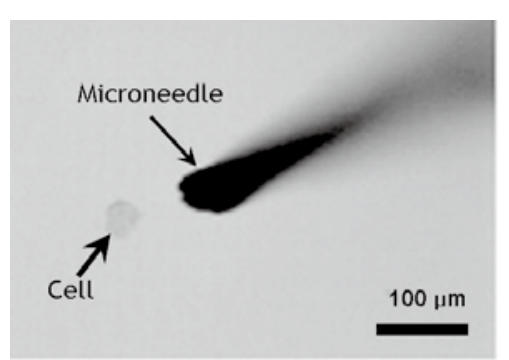

(a)

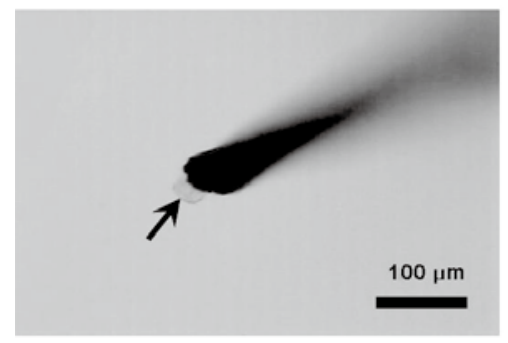

(b)

Fig. 6. Images of a microneedle being used to capture an oral epitherical cell: (a) before and (b) after. 
Table 2

Comparison of volumes and contact angles of water drops generated by a commercial dispensing needle and a fabricated nickel microneedle.

\begin{tabular}{lcc}
\hline & $\begin{array}{c}\text { Commercial } \\
\text { dispensing nozzle }\end{array}$ & $\begin{array}{c}\text { Fabricated } \\
\text { nickel micronozzle }\end{array}$ \\
\hline Needle size & $\begin{array}{l}\text { Inner diameter: } 483 \mu \mathrm{m} \\
\text { Outer diameter: } 711 \mu \mathrm{m}\end{array}$ & $\begin{array}{c}\text { Inner diameter: } 19 \mu \mathrm{m} \\
\text { Outer diameter: } 30 \mu \mathrm{m}\end{array}$ \\
$\begin{array}{l}\text { Drop volume } \\
\text { Contact angle }\end{array}$ & $\begin{array}{l}\text { Commercial } \\
\text { Water drop } \\
\text { (at the end of needle) }\end{array}$
\end{tabular}

\section{Conclusion}

A novel fabrication method for nickel microneedles has been proposed and realized by means of sequential electroless copper and nickel plating on the inner wall of a copper base tube and the etching of the outer copper layer. The inner diameter of the tube decreases as the copper and nickel plating progresses. A sharp nickel microneedle was acquired by selective copper etching at the end of the tube. By applying a temperature gradient along the length of the copper base tube, almost no plating takes place at the cooled inlet while the hot outlet is well plated, resulting in a wide inlet and a sharp end. The diameter of the aperture at the end of the tube can be easily controlled by the plating time. Therefore, microneedles with various diameters can be easily fabricated via the 
proposed fabrication method. To verify the applicability of the fabricated microneedles, they were applied to a probe for cell capturing and a micronozzle for microdispensing, and an oral epithelial cell was successfully captured and delivered. The measured contact angle for the fabricated micronozzle was $6^{\circ}$ higher than that for a commercial needle. The fabricated microneedles are readily applicable to various application areas including microinjectors, microdispensers, microspotters, microprobes, and micronozzles.

\section{Acknowledgement}

This work was supported by grant No. R08-2003-000-10964-0 from the Basic Research Program of the Korea Science and Engineering Foundation. The authors wish to thank Professor Jun-Bo Yoon of Korea Advanced Institute of Science of Technology (KAIST) for the help in copper etching.

\section{References}

1 J. Z. Hilt and N. A. Peppas: Int. J. Pharm. 306 (2005) 15.

2 A. L. Teo, C. Shearwood, K. C. Ng, J. Lu and S. Moochhala: Mater. Sci. Eng., B 132 (2006) 151.

3 M. R. Prausnitz: Adv. Drug Deliv. Rev. 56 (2004) 581.

4 D. M. Cao, T. Wang, B. Feng, W. J. Meng and K. W. Kelly: Thin Solid Films 398-399 (2001) 553.

5 E. V. Mukerjee, S. D. Collins, R. R. Isseroff and R. L. Smith: Sensor Actuat. A-Phys. 114 (2004) 267.

6 J.-H. Park, M. G. Allen and M. R. Prausnitz: J. Controlled Release 104 (2005) 51.

7 B. D. D. Matthews, D. R. Overby, F. J. Alenghat, J. Karavitis, Y. Numaguchi, P. G. Allen and D. E. Ingber: Biochem. Bioph. Res. Co. 313 (2004) 758.

8 A. Doraiswamy, C. Jin, R. J. Narayan, P. Mageswaran, P. Mente, R. Modi, R. Auyeung, D. B. Chrisey, A. Ovsianikov and B. Chichkov: Acta Biomaterialia 2 (2006) 267.

9 S.-J. Paik, S. Byun, J.-M. Lim, Y. Park, A. Lee, S. Chung, J. Chang, K. Chun and D. Cho: Sensor Actuat. A-Phys. 114 (2004) 276.

10 A. Rodriguez, D. Molinero, E. Valera, T. Trifonov, L. F. Marsal, J. Pallares and R. Alcubilla: Sensor Actuat. B-Chem. 109 (2005) 135.

11 A. Yeung, T. Dabros, J. Masliyah and J. Czarnecki: Colloid. Surface. A: Physicochem. Eng. Aspects 174 (2000) 169.

12 M. L. Reed and W.-K. Lye: Proc. IEEE 92 (1) (2004) 58.

13 www.nanopass.com

14 S.-J. Moon and S. S. Lee: Transducers'03: 12th Int. Conf. Solid-State Sensors, Actuators and Microsystems (IEEE, Boston, 2003) p. 1546.

15 F. Vollertsen, H. S. Niehoff and Z. Hu: Int. J. Mach. Tool. Manu. 46 (2006) 1172.

16 F. Vollertsen, Z. Hu, H. S. Niehoff and C. Theiler: J. Mater. Process. Technol. 151 (2004) 70.

17 H. S. Lim, Y. S. Wong, M. Rahman and M. K. E. Lee: J. Mater. Process. Technol. 140 (2003) 318.

18 G.-L. Chern and S.-D. Wang: Precis. Eng. 31 (2007) 210.

19 H. Cho, D.-Y. Hwang, B.-S. Lee and H.-H. Jo: J. Mater. Process. Technol. 187-188 (2007) 645.

20 A. B. Frazier, J. Brazzle, B. K. Gale and I. Papautsky: Int. Device Research Symp. (Charlottesville, VA, 1999) p. 471.

21 K. Kim, D. S. Park, H. M. Lu, W. Che, K. Kim, J.-B. Lee and C. H. Ahn: J. Micromech. Microeng. 14 (2004) 597. 